\title{
Renal dysfunction in early adulthood following birth asphyxia in male spiny mice, and its amelioration by maternal creatine supplementation during pregnancy
}

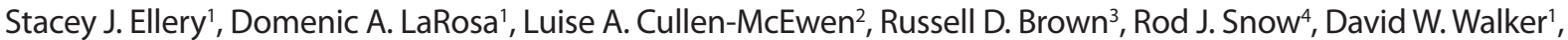 \\ Michelle M. Kett ${ }^{3}$ and Hayley Dickinson ${ }^{1}$
}

\begin{abstract}
BACKGROUND: Acute kidney injury affects $~ 70 \%$ of asphyxiated newborns, and increases their risk of developing chronic kidney disease later in life. Acute kidney injury is driven by renal oxygen deprivation during asphyxia, thus we hypothesized that creatine administered antenatally would protect the kidney from the long-term effects of birth asphyxia.
\end{abstract}

METHODS: Pregnant spiny mice were fed standard chow or chow supplemented with 5\% creatine from 20-d gestation (midgestation). One day prior to term (37-d gestation), pups were delivered by caesarean or subjected to intrauterine asphyxia. Litters were allocated to one of two time-points. Kidneys were collected at 1 mo of age to estimate nephron number (stereology). Renal function (excretory profile and glomerular filtration rate) was measured at 3 mo of age, and kidneys then collected for assessment of glomerulosclerosis.

RESULTS: Compared with controls, at 1 mo of age male (but not female) birth-asphyxia offspring had 20\% fewer nephrons $(P<0.05)$. At 3 mo of age male birth-asphyxia offspring had $31 \%$ lower glomerular filtration rate $(P<0.05)$ and greater glomerular collagen IV content $(P<0.01)$. Antenatal creatine prevented these renal injuries arising from birth asphyxia.

CONCLUSION: Maternal creatine supplementation during pregnancy may be an effective prophylactic to prevent birth asphyxia induced acute kidney injury and the emergence of chronic kidney disease.

A cute kidney injury (AKI) in neonates is a relatively common (50-70\%) consequence of a birth complicated by severe intrapartum hypoxia or asphyxia (1). The presence of AKI following birth asphyxia has been linked to increased rates of morbidity and mortality in the neonatal period (2). The newborn kidney is particularly sensitive to hypoxia and the activation of autonomic reflexes that reduce renal perfusion, as part of the systemic response to maintain blood flow and oxygen supply to the brain, heart, and adrenal glands $(3,4)$. While this response to acute hypoxia can be seen as "adaptive", it nevertheless leads to significant under-perfusion of the kidney, sufficient to place cortical and tubular renal parenchymal cells at risk of necrotic and apoptotic cell injury $(5,6)$, which at birth can lead to AKI.

There is growing evidence that the structural damage associated with neonatal AKI persists and put patients at a much higher risk of developing chronic kidney disease (CKD) later in life (7). It is estimated that between $27-67 \%$ of survivors of neonatal AKI will present with frank or incipient CKD by $3 \mathrm{y}$ of age $(8,9)$. Thus, there is a clear need to develop treatments that not only prevent neonatal AKI, but also reduce its impact on long-term renal health outcomes. Currently, there are no treatments that prevent asphyxia-induced AKI at birth, or promote repair of renal damage in the neonate.

We have previously characterized neonatal AKI at $24 \mathrm{~h}$ after birth asphyxia in the spiny mouse (Acomys cahirinus), a precocial rodent that completes nephrogenesis prior to birth $(10,11)$. AKI in this model was defined by increased intrarenal expression of neutrophil gelatinase-associated lipocalin ( $\mathrm{Ngal}$ ), altered plasma electrolytes and significant structural damage to the renal cortex, medulla, and renal papillae, including the presence of shrunken and absent glomerular tufts in the outer cortex (11). Importantly, this study found that placing pregnant spiny mice on a diet supplemented with $5 \%$ w/w creatine, the guanidine compound essential for maintenance of intracellular ATP under hypoxic conditions, for $17 \mathrm{~d}$ prior to birth completely prevented the AKI induced by birth asphyxia in the neonatal spiny mouse (11).

Confirming that CKD may have a perinatal origin, and preventing the loss of renal function in adult life is therefore of great clinical importance. This study had two aims. Firstly, to confirm what effect, if any, an episode of neonatal AKI has on renal structure and function in adulthood, and; secondly, to determine if the antenatal creatine treatment that prevented neonatal AKI had a legacy that prevented the deterioration of renal function in adult life. We also assessed whether outcomes were sex dependent, as sex differences in the severity of kidney

\footnotetext{
The last two authors contributed equally to this work.

'The Ritchie Centre, Hudson Institute of Medical Research and Department of Obstetrics \& Gynaecology, Monash Medical Centre, Monash University, Melbourne, Australia; ${ }^{2}$ Department of Anatomy and Developmental Biology, Monash University, Clayton Campus, Melbourne, Australia; ${ }^{3}$ Department of Physiology, Monash University, Clayton Campus, Melbourne, Victoria, Australia; ${ }^{4}$ Institute for Physical Activity and Nutrition, Deakin University, Burwood Campus, Melbourne, Australia. Correspondence: Stacey J. Ellery (stacey.ellery@hudson.org.au) Received 22 August 2016; accepted 26 November 2016; advance online publication 1 February 2017. doi:10.1038/pr.2016.268
} 
injury have been shown previously in rodent and human studies of ischemia-reperfusion injury (12-15), and clinical reports suggest a higher propensity for renal illness in male infants and children (9).

\section{METHODS}

\section{Spiny Mice}

All experiments were approved in advance by Monash University Animal Ethics Committee and conducted in accordance with the Australian Code of Practice for the Care and Use of Animals for Scientific Purposes. Spiny mice were bred and housed as previously described (16).

At day 20 of gestation (term $38 \mathrm{~d}$ ), spiny mouse dams were allocated to receive either a diet containing $5 \% \mathrm{w} / \mathrm{w}$ creatine monohydrate (32.44 mg Cr/g; Specialty Feeds, Glen Forrest, Perth, Australia) or remain on standard rodent chow $(2.16 \mathrm{mg} \mathrm{Cr} / \mathrm{g}$; Specialty Feeds, Glen Forrest, Perth, Australia). At day 37 of gestation pups were delivered by caesarean section (controls), or the whole uterus removed and placed in a saline bath $\left(37^{\circ} \mathrm{C}\right)$ to induce $7.5-8 \mathrm{~min}$ of intrauterine hypoxia (birth asphyxia), as previously described $(11,17,18)$. All pups within a litter were cross-fostered to another dam who had remained on a control diet, and who had delivered a litter of comparable size within the preceding 1-24h. Pups were randomly allocated to one of two postnatal outcome time-points: a preweaning time-point at 1-mo postnatal age, or a young adult time-point of 3 mo. To avoid a litter effect, no more than one male and female pup per litter was allocated to either postnatal time-point. Groups were composed of offspring from 7-11 different litters.

\section{Stereological Assessment of Nephron Endowment}

At 1 mo of age, offspring ( $n=6 /$ sex/treatment) were weighed, killed by cervical dislocation and the left kidney weighed and immersion fixed ( $10 \%$ buffered formalin) for $24 \mathrm{~h}$ before being processed to glycolmethacrylate resin. Serial sections $(20 \mu \mathrm{m})$ were then prepared, with every $10^{\text {th }}$ and $11^{\text {th }}$ section sampled and stained with $1 \%$ Periodic Acid Schiffs reagent. Estimated kidney volume, total glomerular number, and glomerular and corpuscle volumes were determined using unbiased stereological techniques as previously described $(19,20)$.

\section{Renal Excretory Function}

At 3 mo postnatal age spiny mice were placed in metabolic cages (Monash Scientific Glass, Dandenong, Victoria) for $24 \mathrm{~h}$ to facilitate urine collection. Food consumption, water intake, and urine and fecal outputs were measured. All spiny mice were acclimatized to the cages prior to beginning urine collection (13). Urine samples were spun down to remove debris, and aliquots stored at $-20^{\circ} \mathrm{C}$ for further analysis.

\section{Urinary Analysis}

Urinary electrolyte concentrations $\left(\mathrm{Na}^{+}, \mathrm{K}^{+}\right.$, and $\left.\mathrm{Cl}-\right)$ were measured using ion selective electrodes (Siemens RAPIDchem 744 electrolyte analyzer; Erlangen, Germany). Urine osmolality was determined by freezing point depression (Osmomat 030 Cyroscopic Osmometer; Gonotec, Berlin, Germany). Urinary protein was determined using the bicinchoninic protein assay according to manufacturer's instructions (BCA Protein Assay Kit\#23225, Thermo Scientific, Scoresby, Australia). All urine analytic concentrations were then adjusted for urine volume to determine 24-h excretion data. Values were expressed as absolute values and per gram body weight.

\section{Transcutaneous Measurement of FITC-Sinistrin Clearance}

One to $2 \mathrm{~d}$ after obtaining the $24 \mathrm{~h}$ urine collections, the elimination kinetics of FITC-sinistrin was measured in these 3 mo old, conscious, spiny mice using a NIC-Kidney device (Mannheim Pharma and Diagnostics, Mannheim, Germany) as an estimate of glomerular filtration rate (GFR) (21). In brief, the day prior to measurement, spiny mice were lightly ( $\sim 5 \mathrm{~min})$ anaesthetized (Isoflurane, $4.5 \%$ induction, $2.1 \%$ maintenance) and fur removed from an area $(\sim 1 \times 1 \mathrm{~cm})$ on the back of the spiny mouse, using depilatory cream. On the day of GFR measurement, spiny mice were briefly ( $\sim 5 \mathrm{~min}$ ) anaesthetized (isoflurane), the photodiode recording device (NIC-Kidney Device) secured to the exposed skin with double-sided adhesive tape before giving an intracardiac injection of FITC-sinistrin $(1.5 \mu \mathrm{l} / \mathrm{g}$ body weight of $35 \mathrm{mg} / \mathrm{ml}$ sinistrin in $0.9 \% \mathrm{NaCl}$; total volume $30-45 \mu \mathrm{l}$ ). Spiny mice were returned to their home cage and the elimination kinetics (halftime, $\left.\mathrm{t}^{1 / 2}\right)$ recorded for the next $1 \mathrm{~h}(22)$.

\section{Collagen IV Immunohistochemistry}

After the completion of a successful FITC-sinistrin clearance measurement, spiny mice were killed via cervical dislocation. Left kidneys were collected, fixed in $10 \%$ buffered formalin and processed to paraffin for histological assessment. Paraffin sections $(4 \mu \mathrm{m})$ were deparaffinized in xylene, permeabilized in $0.3 \%$ Triton X/phosphate buffered saline (PBS; pH 7.4), and antigen retrieval carried out with pepsin $\left(0.1 \%\right.$ in $\left.0.1 \mathrm{~N} \mathrm{HCL}, 37^{\circ} \mathrm{C}, 30 \mathrm{~min}\right)$. Sections were rinsed in $0.1 \mathrm{~mol} / \mathrm{l} \mathrm{PBS}(\mathrm{pH} 7.4)$, incubated with $0.3 \%$ hydrogen peroxide (20 min at room temperature), and then incubated with DAKO block ( $30 \mathrm{~min}$ at room temperature). Sections were probed for $12 \mathrm{~h}$ at $4^{\circ} \mathrm{C}$ with $1: 1,000$ dilution of rabbit polyclonal Collagen IV primary antibody (Abcam; Melbourne, Australia) in DAKO antibody diluent (Agilent Technologies; Braeside, Australia). The sections were then washed 3 times in PBS and incubated for $1 \mathrm{~h}$ at room temperature with 1 : 200 dilution of goat-anti rabbit polyclonal secondary antibody (Wako; Richmond, VA). Antibody binding was visualized following a $1 \mathrm{~h}$ incubation by amplifying the target antibody signal with Avidin-Biotin Complex (Thermofisher Scientific; Scoresby, Victoria, Australia), using 3,3'-diaminobenzidine (DAB). Sections were imaged using a bright field microscope with constant light settings. Images were converted to gray scale and the mean optical density of positive staining/mean area for 20 -glomeruli/per section were measured with the investigator blinded to the treatment group and sex of the sample (23).

\section{Data Analysis and Statistics}

Data are represented as mean \pm SEM for all data except the stereology, which is presented as mean $\pm \mathrm{SD}$, as this is conventional practice for the representation of these count measurements (20). Data were assessed by Three-way ANOVA, to establish the effects of mode of birth $\left(P_{\mathrm{BIRTH}}\right)$, maternal diet $\left(P_{\mathrm{DIET}}\right)$, and sex of offspring $\left(P_{\mathrm{SEX}}\right)$. Sex of the offspring significantly interacted with the effects of birth asphyxia for stereological and GFR measures. Therefore, data has been presented split for sex, and a Two-way ANOVA used to assess the effects of birth asphyxia $\left(P_{\text {BIRTH }}\right)$ and maternal diet $\left(P_{\mathrm{DIET}}\right)$ for the male and female offspring. Post hoc analysis with Tukey's multiple comparisons was conducted when a significant interaction between the two parameters was identified. All statistical comparisons were conducted using Prism 6 Graphpad software. $P \leq 0.05$ was accepted for statistical significance.

\section{RESULTS}

\section{Kidney Size and Glomerular Structure}

At 1 mo of age, the mode of delivery or maternal diet had no significant effect on body or kidney weights, although females tended to be slightly heavier after the asphyxic birth compared with their C-section delivered counterparts $\left(P_{\mathrm{BIRTH}}=0.053\right.$; Table 1). Female C-section and birth asphyxia offspring from creatine-supplemented mothers had significantly greater kidney volume compared with their control diet counterparts $\left(P_{\text {DIET }}<0.05\right)$. For males, the antenatal creatine diet was associated with a slight but significantly higher kidney-to-body weight ratio at 1 mo of age $\left(P_{\mathrm{DIET}}<0.05\right.$; Table 1$)$, but total kidney volume was similar for males between all groups.

Birth asphyxia had significant effects on glomerular structure at 1 mo of age (Table 2). Glomerular number was reduced by $20 \%$ in male offspring after birth asphyxia, a reduction that was not present for males from creatine-treated mothers (MD $(-1,970), 95 \%$ CI $(-3808,-131), P_{\text {BIRTH }}(<0.05), P_{\text {DIET }}(<0.05)$, $\left.P_{\text {INT }}(<0.05)\right)$. Birth asphyxia was associated with an increase in 
Table 1. Body mass, kidney weight and volume at 1 mo of age

\begin{tabular}{|c|c|c|c|c|c|c|c|c|}
\hline & \multirow[b]{2}{*}{ Sex } & \multicolumn{2}{|c|}{ Control diet } & \multicolumn{2}{|c|}{ Creatine diet } & \multicolumn{3}{|c|}{ Statistics } \\
\hline & & C-section & Asphyxia & C-section & Asphyxia & $P_{\text {Birth }}$ & $P_{\text {DIET }}$ & $P_{\text {INT }}$ \\
\hline \multirow[t]{2}{*}{ Body weight (g) } & Male & $24.3 \pm 3.9$ & $26.0 \pm 2.7$ & $21.5 \pm 3.6$ & $24.4 \pm 3.5$ & NS & NS & NS \\
\hline & Female & $22.7 \pm 1.6$ & $25.2 \pm 4.1$ & $22.3 \pm 3.0$ & $25.0 \pm 3.1$ & 0.053 & NS & NS \\
\hline \multirow[t]{2}{*}{ Kidney weight (mg) } & Male & $120.8 \pm 23.0$ & $119.0 \pm 13.6$ & $119.8 \pm 23.5$ & $138.3 \pm 16.5$ & NS & NS & NS \\
\hline & Female & $111.6 \pm 8.8$ & $126.3 \pm 14.0$ & $116.5 \pm 21.4$ & $124.8 \pm 10.7$ & NS & NS & NS \\
\hline \multirow[t]{2}{*}{ KW:BW (mg/g) } & Male & $4.95 \pm 0.23$ & $4.62 \pm 0.71$ & $5.17 \pm 0.32$ & $5.39 \pm 0.43$ & NS & $<0.05$ & NS \\
\hline & Female & $4.93 \pm 0.56$ & $5.06 \pm 0.52$ & $5.22 \pm 0.58$ & $5.02 \pm 0.50$ & NS & NS & NS \\
\hline \multirow[t]{2}{*}{ Estimated kidney volume $\left(\mathrm{mm}^{3}\right)$} & Male & $68.2 \pm 17.6$ & $79.3 \pm 20.3$ & $81.2 \pm 16.5$ & $81.0 \pm 12.5$ & NS & NS & NS \\
\hline & Female & $69.8 \pm 12.7$ & $70.2 \pm 6.4$ & $78.2 \pm 2.9$ & $79.8 \pm 10.1$ & NS & $<0.05$ & NS \\
\hline
\end{tabular}

Characteristics of kidney structure at the time of stereological analysis (1 mo of age). KW:BW - kidney weight to body weight ratio. Values are mean \pm SD; $n=6 /$ group. Statistical analysis, Two-way ANOVA to assess the effects of birth asphyxia $\left(P_{\text {BIRTH }}\right)$, maternal diet $\left(P_{\text {DIET }}\right)$ and whether there was an interaction between the two independent variables $\left(P_{\text {INT }}\right)$. Significance $P \leq 0.05$.

Table 2. Stereological analysis of glomerular number and size at 1 mo of age

\begin{tabular}{|c|c|c|c|c|c|c|c|c|}
\hline & Sex & \multicolumn{2}{|c|}{ Control diet } & \multicolumn{2}{|c|}{ Creatine diet } & \multicolumn{3}{|c|}{ Statistics } \\
\hline \multirow[t]{2}{*}{ Glomerular number (Nglom) } & Male & $10,926 \pm 423$ & $8,869 \pm 526$ & $10,952 \pm 464$ & $10,839 \pm 439$ & $<0.05$ & $<0.05$ & $<0.05$ \\
\hline & Female & $10,503 \pm 405$ & $10,283 \pm 642$ & $10,460 \pm 685$ & $10,300 \pm 614$ & NS & NS & NS \\
\hline \multirow[t]{2}{*}{ Glomerular volume $\left(\mathrm{mm}^{3} \times 10^{-4}\right)$} & Male & $1.82 \pm 0.33$ & $2.25 \pm 0.43$ & $1.89 \pm 0.37$ & $2.12 \pm 0.29$ & $<0.05$ & NS & NS \\
\hline & Female & $1.78 \pm 0.23$ & $2.19 \pm 0.35$ & $2.24 \pm 0.29$ & $2.31 \pm 0.46$ & NS & $<0.05$ & NS \\
\hline Total glomerular volume $\left(\mathrm{mm}^{3}\right)$ & Female & $1.86 \pm 0.20$ & $2.15 \pm 0.29$ & $2.31 \pm 0.16$ & $2.33 \pm 0.26$ & NS & $<0.01$ & NS \\
\hline \multirow[t]{2}{*}{ Corpuscle volume $\left(\mathrm{mm}^{3} \times 10^{-4}\right)$} & Male & $1.90 \pm 0.34$ & $2.37 \pm 0.54$ & $2.00 \pm 0.36$ & $2.19 \pm 0.32$ & $<0.05$ & NS & NS \\
\hline & Female & $1.87 \pm 0.29$ & $2.19 \pm 0.35$ & $2.32 \pm 0.33$ & $2.39 \pm 0.48$ & NS & $<0.05$ & NS \\
\hline Total corpuscle Volume $\left(\mathrm{mm}^{3}\right)$ & Male & $2.06 \pm 0.35$ & $2.08 \pm 0.45$ & $2.17 \pm 0.33$ & $2.39 \pm 0.50$ & NS & NS & NS \\
\hline
\end{tabular}

Characterization of glomerular number and size at 1 mo of age, using unbiased stereology. Values are mean \pm SD; $n=6 / g r o u p$. Statistical analysis, Two-way ANOVA to assess the effects of birth asphyxia $\left(P_{\text {BIRTH }}\right)$ maternal diet $\left(P_{\text {DIET }}\right)$ and whether there was an interaction between the two independent variables $\left(P_{\text {INT }}\right)$. Significance $P \leq 0.05$.

the mean glomerular volume in male offspring $\left(P_{\text {BIRTH }}<0.05\right)$. The higher mean glomerular volume in the birth asphyxiacontrol males offset the lower glomerular number, such that estimated total glomerular volume values were not different between the groups (Table 2). Birth asphyxia had no effect on glomerular number or volume in female offspring, although the prenatal creatine diet significantly increased renal glomerular and corpuscle volume at 1 mo of age (Table 2).

To determine if glomeruli showed signs of fibrosis, glomerular collagen IV content was assessed by immunohistochemistry at 3 mo of age, equivalent to early adulthood in the spiny mouse. For males from control diet mothers, collagen IV content of glomeruli was twofold higher following birth asphyxia compared with the C-section controls (MD $(-1.87)$, 95\% CI $(-2.99,-0.74), P_{\text {BIRTH }}(<0.01)$; Figure $\left.1 \mathrm{a}, \mathrm{c}, \mathrm{d}\right)$. In contrast, there was no effect of birth asphyxia on glomerular collagen IV in males from creatine-supplemented mothers $\left(P_{\text {DIET }}<0.01, P_{\text {INT }}\right.$ $<0.05$; Figure 1a,f). Neither the mode of birth or maternal diet had any significant effect on glomerular collagen IV in female spiny mice at 3 mo of age (Figure $1 \mathbf{b}$ ).

\section{Renal Function}

At 3 mo of age (early adult), there were no significant effects of mode of birth or prenatal creatine exposure on water intake, urine output, urinary electrolyte or protein excretion or urinary osmolality across the groups (Table 3). For male offspring, significant interactions were obtained for both body weight $\left(P_{\mathrm{INT}}<0.05\right)$ and food intake $\left(P_{\mathrm{INT}}<0.05\right)$ measures. However, no specific determinants of the interactions could be identified with further post hoc analysis. When assessing conscious renal function in this cohort, there was a significant effect of birth asphyxia on FITC-sinistrin clearance and thus estimated GFR in males born of control-diet dams. Male birth asphyxia-control diet spiny mice had a $24 \%$ higher $\mathrm{t}^{1 / 2}$ of FITCsinistrin compared with C-section controls (MD (-6.21), 95\% CI $(-11.69,-0.73), P_{\text {BIRTH }}(<0.01)$; Figure 2a $)$, and estimated 

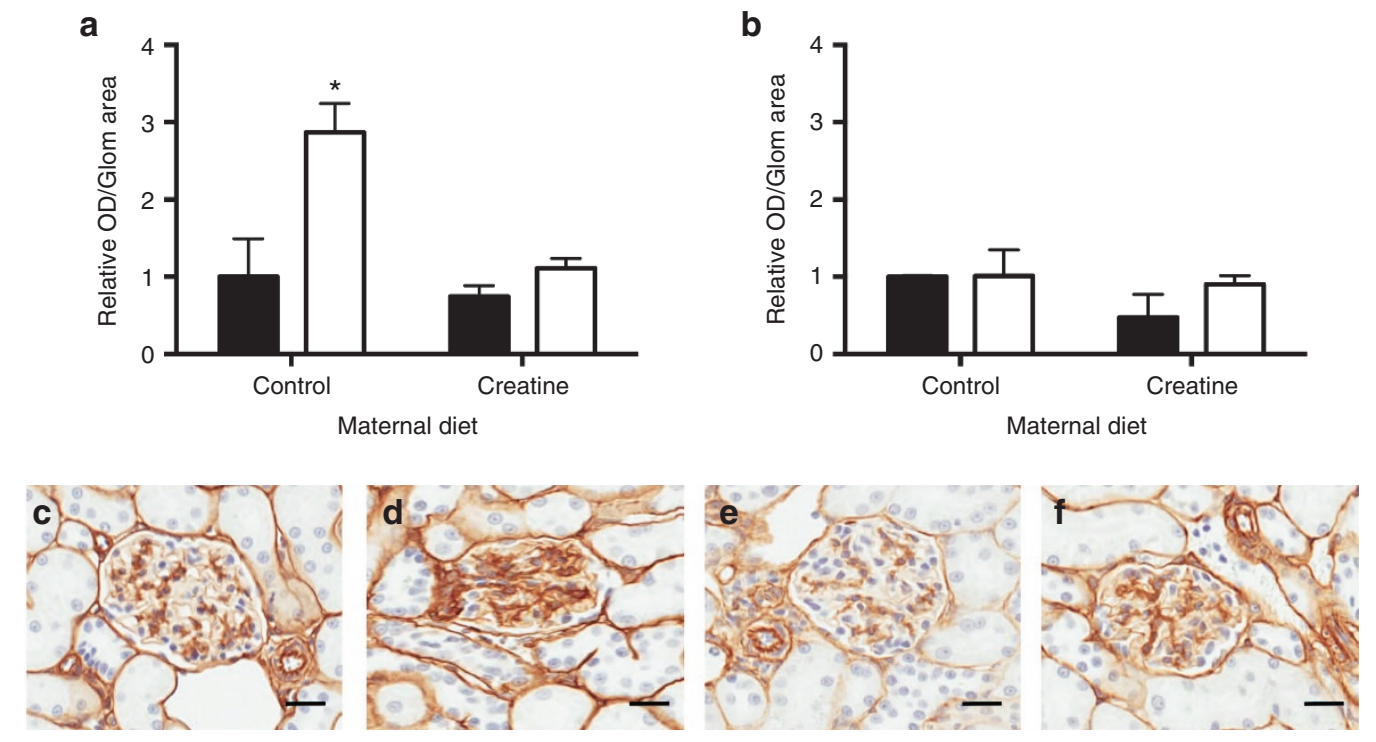

Figure 1. Glomerular Collagen IV Deposition. Mean optical density of collagen IV, expressed relative to c-section control-diet cohorts for male and female spiny mouse offspring at 3 mo postnatal age are present in graphs $(\mathbf{a})$ and $(\mathbf{b})$, respectively. Closed bars $=c$-section groups and hatched bars $=$ birth asphyxia groups. Values are mean $\pm \mathrm{SEM} ; n=6 /$ group. Statistical analysis, Two-way ANOVA to assess the effects of birth asphyxia $\left(P_{\text {BIRTH }}\right)$ maternal $\operatorname{diet}\left(\mathrm{P}_{\text {DIET }}\right)$ and whether there was an interaction between the two independent variables $\left(\mathrm{P}_{\text {INT }}\right)$. Significance $P \leq 0.05$; ${ }^{*}$ represents $P \leq 0.05$ with post hoc analysis. Figure $a_{;} P_{B I R T H}<0.01 P_{D I E T}<0.01$ and $P_{I N T}<0.05$. The subsequent panels display representative images of glomerular collagen IV staining in male c-section (c), birth asphyxia (d), C-section-creatine (e) and birth asphyxia-creatine (f) sections. Scale bars $=2 \mu \mathrm{M}$.

Table 3. Analysis of food and water intake, and urine output and composition at 3 mo of age

\begin{tabular}{|c|c|c|c|c|c|c|c|c|}
\hline \multirow{2}{*}{$\begin{array}{l}3 \text { mo metabolic } \\
\text { cage analysis }\end{array}$} & \multirow[b]{2}{*}{ Sex } & \multicolumn{2}{|c|}{ Control diet } & \multicolumn{2}{|c|}{ Creatine diet } & \multicolumn{3}{|c|}{ Statistics } \\
\hline & & C-section & Asphyxia & C-section & Asphyxia & $P_{\text {BIRTH }}$ & $P_{\text {DIET }}$ & $P_{\mathrm{INT}}$ \\
\hline & & Metabolic & Cage & Parameters & & & & \\
\hline Body weight (g) & Female & $30.3 \pm 1.0$ & $31.1 \pm 0.8$ & $31.0 \pm 0.7$ & $32.7 \pm 0.9$ & NS & NS & NS \\
\hline Urine output & Male & $32.5 \pm 6.8$ & $32.0 \pm 2.2$ & $27.8 \pm 2.8$ & $30.9 \pm 5.1$ & NS & NS & NS \\
\hline Water intake & Male & $89.3 \pm 12.5$ & $77.1 \pm 5.7$ & $88.7 \pm 5.3$ & $80.8 \pm 9.2$ & NS & NS & NS \\
\hline$(\mu \mathrm{l} / \mathrm{gBW} / 24 \mathrm{~h})$ & Female & $93.3 \pm 7.3$ & $89.0 \pm 4.5$ & $88.4 \pm 7.2$ & $93.2 \pm 8.3$ & NS & NS & NS \\
\hline Food intake & Male & $77.0 \pm 7.6$ & $79.8 \pm 5.0$ & $75.6 \pm 8.4$ & $62.0 \pm 4.1$ & NS & NS & $<0.05$ \\
\hline \multirow[t]{2}{*}{ (mg/gBW/24h) } & Female & $81.2 \pm 3.5$ & $81.1 \pm 8.2$ & $75.6 \pm 4.0$ & $69.6 \pm 5.3$ & NS & NS & NS \\
\hline & & Urinary & Excretion & Profile & & & & \\
\hline$(\mu \mathrm{mol} / \mathrm{gBW} / 24 \mathrm{~h})$ & Female & $1.46 \pm 0.63$ & $4.11 \pm 1.23$ & $1.88 \pm 0.48$ & $2.45 \pm 0.57$ & NS & NS & NS \\
\hline $\mathrm{U}_{\mathrm{K}}^{+}$excretion & Male & $7.36 \pm 1.50$ & $6.55 \pm 0.59$ & $5.69 \pm 0.46$ & $5.22 \pm 0.36$ & NS & NS & NS \\
\hline$(\mu \mathrm{mol} / \mathrm{gBW} / 24 \mathrm{~h})$ & Female & $5.06 \pm 0.98$ & $6.82 \pm 1.04$ & $5.12 \pm 1.03$ & $6.71 \pm 0.85$ & NS & NS & NS \\
\hline $\mathrm{U}_{\mathrm{Cl}}{ }^{-}$excretion & Male & $6.42 \pm 1.12$ & $6.65 \pm 0.42$ & $5.55 \pm 0.56$ & $4.77 \pm 0.31$ & NS & NS & NS \\
\hline$(\mu \mathrm{mol} / \mathrm{gBW} / 24 \mathrm{~h})$ & Female & $4.12 \pm 0.80$ & $6.50 \pm 1.17$ & $4.52 \pm 0.88$ & $6.13 \pm 1.09$ & NS & NS & NS \\
\hline $\mathrm{U}_{\text {PRO }}$ excretion & Male & $19.0 \pm 2.9$ & $16.1 \pm 0.9$ & $16.4 \pm 0.9$ & $16.4 \pm 2.1$ & NS & NS & NS \\
\hline$(\mu \mathrm{g} / \mathrm{gBW} / 24 \mathrm{~h})$ & Female & $14.4 \pm 3.3$ & $16.8 \pm 2.9$ & $15.3 \pm 4.2$ & $15.4 \pm 1.3$ & NS & NS & NS \\
\hline
\end{tabular}

Fluid intake, food consumption, urine production, and urine excretion profile in male and female spiny mouse offspring at 3 mo of age. Values are mean \pm SEM; $n=6 / g r o u p$. Statistical analysis, two-way ANOVA to assess the effects of birth asphyxia $\left(P_{\text {BIRTH }}\right)$ maternal diet $\left(P_{\text {DIET }}\right)$ and whether there was an interaction between the two independent variables $\left(P_{\text {INT }}\right)$. Significance $P \leq 0.05$. 
a

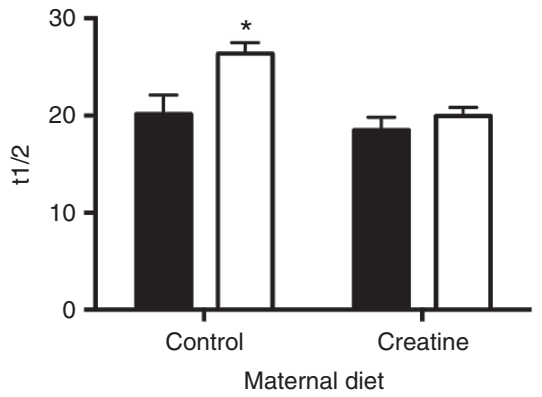

C

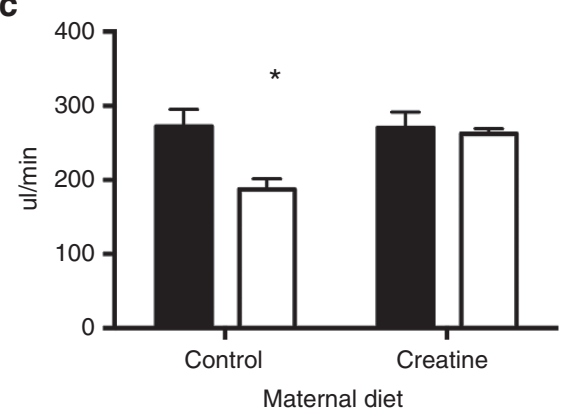

b

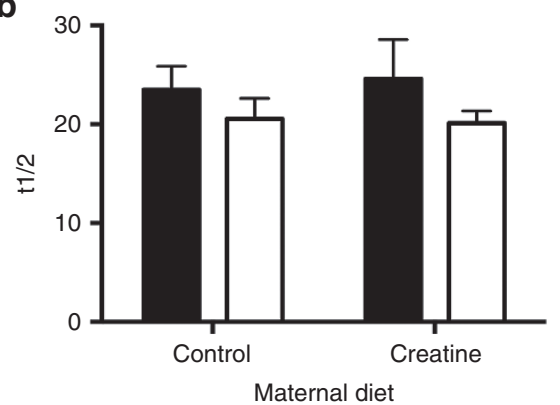

b

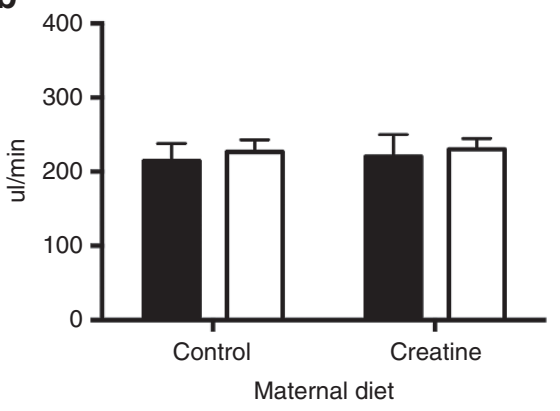

Figure 2. FITC-sinistrin clearance rate and estimated glomerular filtration rate (GFR). The $\mathrm{t}^{1 / 2}$ of FITC-sinistrin clearance of male (a) and female (b) offspring at 3 mo of age, determined by the elimination kinetics curve generated via transcutaneous measures. Estimated GFR of male (c) and female (d) offspring was calculated from the $\mathrm{t}^{1 / 2}$ of FITC-sinistrin and corrected for body weight. Closed bars $=\mathrm{c}$-section groups and hatched bars $=$ birth asphyxia groups. Values are mean $\pm \mathrm{SEM} ; n=6 /$ group. Statistical analysis, Two-way ANOVA to assess the effects of birth asphyxia $\left(P_{\text {BIRTH }}\right)$, maternal diet $\left(P_{\text {DIET }}\right)$, and whether there was an interaction between the two independent variables $\left(P_{\text {INT }}\right)$. Significance $P \leq 0.05$; ${ }^{*}$ represents $P \leq 0.05$ with post hoc analysis. Figure $\mathbf{a} ; P_{\mathrm{BITTH}}<0.01, P_{\mathrm{DIET}}<0.001$, and $P_{\mathrm{INT}}<0.1$. Figure $\mathbf{c}_{;} P_{\mathrm{BIRTH}}<0.01, P_{\mathrm{DIET}}<0.01$ and $P_{\mathrm{INT}}<0.05$.

GFR calculated relative to body weight was $31 \%$ lower in this group $(269.4 \pm 24.3 \mu \mathrm{l} / \mathrm{min}, 187.1 \pm 14.4 \mu \mathrm{l} / \mathrm{min}$ respectively; $P_{\text {BIRTH }}<0.01$; Figure 2c). In contrast $\mathrm{t}^{1 / 2}$ FITC-sinistrin clearance and estimated GFR $(262.7 \pm 9.3 \mu \mathrm{l} / \mathrm{min})$ of males who had undergone birth asphyxia and had been born to mothers fed the creatine diet was not different from controls. Furthermore, prenatal creatine exposure had no effect on GFR, since the clearance of FITC-sinistrin was not different in the offspring from control diet and creatine supplemented dams, irrespective of mode of birth (Figure 2a,c). Neither birth asphyxia nor creatine supplementation affected FITC-sinistrin clearance or calculated GFR in female offspring (Figure 2b,d).

\section{DISCUSSION}

We have previously shown that fetal asphyxia at birth in the spiny mouse causes renal injury with some of the cardinal features of neonatal AKI (11), and that this outcome from birth asphyxia was not present in neonates from mothers that had received supplementary creatine in their diet during pregnancy. While this study demonstrated the potential to prevent asphyxia-related kidney injury at birth, it remained important to know: (i), what effect, if any, acute renal injury at birth has on renal function in adulthood, and (ii) if the protective benefit of creatine persists into early adulthood in spiny mice offspring. The first significant finding of this study is that birth asphyxia led to marked structural changes in the kidneys of male offspring, including reduced nephron number and glomerular hypertrophy with evidence of glomerulosclerosis. These changes were associated with a functional deficit (reduced GFR) at 3 mo of age. These outcomes were not present in females after birth asphyxia. Secondly, maternal dietary creatine supplementation during gestation prevented the loss of nephrons and renal dysfunction in the adult male offspring. The results of this study show that the male kidney is particularly vulnerable to the effects of hypoxic/asphyxial injury at birth, and that creatine supplementation during pregnancy provides a protection that persists, and may therefore prevent the progression to CKD in adult life.

Loss of nephrons is a major risk factor for CKD (24). In this study male birth asphyxia offspring had a $20 \%$ loss of nephrons at 1 mo of age. Renal pathology involving nephron loss often results in a subsequent increase in single nephron GFR and glomerular hypertrophy as an adaptive mechanism that maintains the overall GFR (25). This compensatory response has been linked to the eventual development of CKD because the increased intracapillary hydraulic pressure leads to gradual and progressive damage to glomerular capillary walls, and hence to glomerulosclerosis $(24,26,27)$. The glomerular hypertrophy and increased collagen IV deposition in the glomeruli of observed male birth asphyxia offspring at 3 mo of age in this study suggests these adaptations to glomerular structure and function were instigated by renal injury at birth. Thus, the $30 \%$ lower GFR, and increased collagen IV accumulation in the glomeruli of male birth asphyxia offspring are particularly significant findings, confirming that an early reduction in nephron number predisposes the young adult kidney to 
glomerulosclerosis and CKD-like outcomes. Such early compromise to renal function is also likely to render the kidney more susceptible to a secondary insult arising from poor adult diet, lifestyle choices, and exposure to nephrotoxic drugs.

In contrast to the marked structural and functional changes observed in the male kidney, the female kidney appears to be largely resistant to the adverse effects of birth asphyxia, demonstrating normal glomerular morphology and renal function at 1 and 3 mo of age, respectively. Neonatal morbidity and mortality is well known to be skewed toward increased survival of female infants (28-31). Normal renal hemodynamics also differs between the sexes, with females displaying lower whole kidney and single nephron GFR when compared with males (13). It has been suggested that the lower functional demand on renal hemodynamics in the female affords some protection against progressive injury following an insult to the kidney (32). Physiological differences between sexes were indeed evident in this study, with female spiny mice from the C-section, control-diet group having a lower GFR than their male control counterparts. An increased male susceptibility to kidney injury has been previously described in other spiny mouse models of perinatal injury. For example, in utero exposure to a high level of glucocorticoids during pregnancy produced an increased heart rate in adult male but not female spiny mouse offspring (33). Increases in GFR after exposure to a high salt diet have also been reported in adult male spiny mice, while females were not affected by this salt exposure (13). Similarly, sexual dimorphism has been identified in the renal responses to adult ischemic reperfusion (I/R) injury $(14,15)$. It is highly likely that the pathophysiology of adult $\mathrm{I} / \mathrm{R}$ injury is comparable to the intrarenal conditions that follow birth asphyxia when renal blood flow is curtailed by the hypoxia-driven autonomic reflexes $(3,4)$. Collectively, these observations provide evidence for why renal injury was not observed in the birth asphyxia females analyzed in this study. However, it remains unknown whether female spiny mice that underwent birth asphyxia would show signs of kidney deterioration in later life.

The key finding of this study is that creatine supplementation for $2.5 \mathrm{wk}$ prior to delivery protected male birth asphyxia offspring from an irreversible loss of nephrons and a reduction in GFR later in life. These observations confirm that injury to the kidney at birth has a legacy that presents as poor renal function in the adult, and that directly preventing this injury in the neonate may be sufficient to avoid a CKD-like outcome in adulthood. The intracellular functions of the creatine phosphocreatine/creatine kinase circuit, and its capacity to reduce hypoxic-ischemic injury, have been well characterized (34). Briefly, in the form of phosphocreatine ( $\mathrm{PCr}$ ), creatine donates a phosphate group allowing regeneration of ATP from ADP (35). Increasing dietary creatine consumption increases the intracellular pool of creatine/phosphocreatine available for ATP resynthesis and can prolong cellular energy homeostasis during episodes of severe hypoxia and hypoperfusion (34). The rephosphorylation of ADP by phosphocreatine also reduces intracellular acidity, particularly during hypoxia, by utilizing a proton $\left(\mathrm{PCr}+\mathrm{MgADP}+\mathrm{H}^{+} \rightarrow\right.$ creatine $\left.+\mathrm{MgATP}\right)$, thus maintaining intracellular acid-base balance (35). Finally, creatine is a mild antioxidant, quenching superoxide to protect mitochondria from oxidative stress (36). These properties have seen creatine supplementation be considered as a treatment for a range of adult diseases, for which cellular energy depletion underpin pathologies. These included neurodegenerative disorders and myopathies (37). Indeed, in the spiny mouse model of birth asphyxia we have demonstrated that maternal creatine supplementation during gestation also minimizes neural injury (17), damage to the diaphragm muscle $(18,38)$ and deleterious remodeling of the skeletal musculature (39).

It should be noted that maternal creatine supplementation also increased total glomerular and corpuscle volumes in male and female offspring, irrespective of mode of birth. Importantly, these morphological changes were not associated with collagen IV accumulation, nor were they linked to altered urinary excretory function or glomerular filtration rate; thus they appear to be of no consequence to renal function in early adulthood in the spiny mouse. While these studies and others suggest creatine supplementation during pregnancy is safe for the mother and fetus (40-42), and that it does not negatively impact renal function $(42,43)$ in adults, further exploration of the mechanisms driving these changes in the renal architecture should be considered.

While this study endeavored to fully characterize the longerterm impact of birth asphyxia on renal structure and function, the single time-point of GFR measurement could be considered as a limitation. Future directions of this preclinical work should include studies of renal hemodynamics, single glomerular filtration and hydrostatic pressures, to determine the association between morphological changes observed in the male birth asphyxia offspring at 1 mo of age, and the decreased GFR apparent at 3 mo of age.

Studies are also underway to assess the safety and efficacy of creatine supplementation during pregnancy, and need to be completed before clinical translation of this study is to be considered. These studies should include comprehensive assessment of physiology and toxicology in the pregnant subject. What the minimal dose of creatine required to provide protection to the neonate following birth asphyxia is, and what the normal levels of creatine during pregnancy are, in human pregnancies, have thus become the prime focus of our current studies.

\section{Conclusion}

These findings in the precocial spiny mouse support recent clinical data suggesting an episode of AKI in the neonatal period increases the risk of developing CKD later in life (7-9). Structural disturbances observed in the neonatal spiny mouse kidney $24 \mathrm{~h}$ after birth asphyxia persists as a reduction in nephron number in male but not female offspring at 1 mo of age. A reduction of GFR by $\sim 30 \%$ and signs of glomerulosclerosis were evident at 3 mo of age in male birth asphyxia offspring. Proteinuria, or abnormal urine electrolyte excretion or osmolality could not be linked to these observations. Maternal 
creatine supplementation prevented the emergence of poor renal function in early adult life in this preclinical model of kidney injury. With further consideration of the safety and efficacy of maternal creatine supplementation during pregnancy, this treatment may prove useful in reducing neonatal AKI secondary to birth asphyxia in human infants, and risk of developing CKD in the adult.

\section{ACKNOWLEDGMENTS}

The authors thank Annike Griffey for her technical assistance in the laboratory, Xiaochu Cai for help with the analysis of GFR data, and the Hudson Institute Histology Platform.

\section{STATEMENT OF FINANCIAL SUPPORT}

This work was supported by the Victorian Government's Operational Infrastructure Support Program to Hudson Institute of Medical Research, an Australia National Health and Medical Research Council (NHMRC) project grant to H.D., and a Cerebral Palsy Alliance Project Grant to H.D.. During these studies S.J.E. and D.L. were supported by Australian Postgraduate Award scholarships, H.D. by an NHMRC Career Development Fellowship and Cerebral Palsy Alliance (Career Development Award), and D.W.W. was supported by the Cerebral Palsy Alliance (Distinguished Researcher) award.

Disclosure: There is no conflict of interest to disclose.

\section{REFERENCES}

1. Aggarwal A, Kumar P, Chowdhary G, Majumdar S, Narang A. Evaluation of renal functions in asphyxiated newborns. J Trop Pediatr 2005;51: 295-9.

2. Periman JM, Tack ED. Renal injury in the asphyxiated newborn infant: Relationship to neurologic outcome. J Pediatr 1988;113:875-9.

3. Gouyon JB, Guignard JP. Management of acute renal failure in newborns. Pediatr Nephrol 2000;14:1037-44.

4. Behrman RE, Lees MH, Peterson EN, De Lannoy CW, Seeds AE. Distribution of the circulation in the normal and asphyxiated fetal primate. Am J Obstet Gynecol 1970;108:956-69.

5. Saikumar P, Venkatachalam MA. Role of apoptosis in hypoxic/ischemic damage in the kidney. Semin Nephrol 2003;23:511-21.

6. Sweetman DU, Riordan M, Molloy EJ. Management of renal dysfunction following term perinatal hypoxia-ischaemia. Acta Paediatr 2013;102: 233-41.

7. Polito C, Papale MR, La Manna A. Long-term prognosis of acute renal failure in the full-term neonate. Clin Pediatr (Phila) 1998;37:381-5.

8. Askenazi DJ. Do children with acute kidney injury require long-term evaluation for CKD? Am J Kidney Dis 2012;59:478-80.

9. Mammen C, Al Abbas A, Skippen P, et al. Long-term risk of CKD in children surviving episodes of acute kidney injury in the intensive care unit: a prospective cohort study. Am J Kidney Dis 2012;59:523-30.

10. Dickinson H, Walker DW, Cullen-McEwen L, Wintour EM, Moritz K. The spiny mouse (Acomys cahirinus) completes nephrogenesis before birth. Am J Physiol Renal Physiol 2005;289:F273-9.

11. Ellery SJ, Ireland Z, Kett MM, Snow R, Walker DW, Dickinson H. Creatine pretreatment prevents birth asphyxia-induced injury of the newborn spiny mouse kidney. Pediatr Res 2013;73:201-8.

12. Dickinson H, Walker DW, Wintour EM, Moritz K. Maternal dexamethasone treatment at midgestation reduces nephron number and alters renal gene expression in the fetal spiny mouse. Am J Physiol Regul Integr Comp Physiol 2007;292:R453-61.

13. Dickinson H, Moritz KM, Kett MM. A comparative study of renal function in male and female spiny mice - sex specific responses to a high salt challenge. Biol Sex Differ 2013;4:21.

14. Müller V, Losonczy G, Heemann U, et al. Sexual dimorphism in renal ischemia-reperfusion injury in rats: possible role of endothelin. Kidney Int 2002;62:1364-71.

15. Park KM, Kim JI, Ahn Y, Bonventre AJ, Bonventre JV. Testosterone is responsible for enhanced susceptibility of males to ischemic renal injury. J Biol Chem 2004;279:52282-92.
16. Dickinson H, Walker D. Managing a colony of spiny mice (Acomys cahirinus) for perinatal research. Australian and New Zealand Council for the Care of Animals in Research and Training (ANZCCART) News 2007;20:4-11.

17. Ireland Z, Castillo-Melendez M, Dickinson H, Snow R, Walker DW. A maternal diet supplemented with creatine from mid-pregnancy protects the newborn spiny mouse brain from birth hypoxia. Neuroscience 2011;194:372-9.

18. Cannata DJ, Ireland Z, Dickinson H, et al. Maternal creatine supplementation from mid-pregnancy protects the diaphragm of the newborn spiny mouse from intrapartum hypoxia-induced damage. Pediatr Res 2010;68:393-8.

19. Gundersen HJ, Bagger P, Bendtsen TF, et al. The new stereological tools: disector, fractionator, nucleator and point sampled intercepts and their use in pathological research and diagnosis. APMIS 1988;96:857-81.

20. Bertram JF. Analyzing renal glomeruli with the new stereology. Int Rev Cytol 1995;161:111-72.

21. Schreiber A, Shulhevich Y, Geraci S, et al. Transcutaneous measurement of renal function in conscious mice. Am J Physiol Renal Physiol 2012;303:F783-8.

22. Ellery SJ, Cai X, Walker DD, Dickinson H, Kett MM. Transcutaneous measurement of glomerular filtration rate in small rodents: through the skin for the win? Nephrology (Carlton) 2015;20:117-23.

23. Chow F, Ozols E, Nikolic-Paterson DJ, Atkins RC, Tesch GH. Macrophages in mouse type 2 diabetic nephropathy: correlation with diabetic state and progressive renal injury. Kidney Int 2004;65:116-28.

24. Brenner BM, Lawler EV, Mackenzie HS. The hyperfiltration theory: a paradigm shift in nephrology. Kidney Int 1996;49:1774-7.

25. Hostetter TH, Olson JL, Rennke HG, Venkatachalam MA, Brenner BM. Hyperfiltration in remnant nephrons: a potentially adverse response to renal ablation. Am J Physiol 1981;241:F85-93.

26. Hayslett JP. Functional adaptation to reduction in renal mass. Physiol Rev 1979;59:137-64.

27. Morrison AB. Experimental chronic renal insufficiency. Methods Achiev Exp Pathol 1966;1:455-75.

28. McMillen MM. Differential mortality by sex in fetal and neonatal deaths. Science 1979;204:89-91.

29. Naeye RL, Burt LS, Wright DL, Blanc WA, Tatter D. Neonatal mortality, the male disadvantage. Pediatrics 1971;48:902-6.

30. Balsara SL, Faerber JA, Spinner NB, Feudtner C. Pediatric mortality in males versus females in the United States, 1999-2008. Pediatrics 2013;132:631-8.

31. Eriksson JG, Kajantie E, Osmond C, Thornburg K, Barker DJ. Boys live dangerously in the womb. Am J Hum Biol 2010;22:330-5.

32. Munger K, Baylis C. Sex differences in renal hemodynamics in rats. Am J Physiol 1988;254(2 Pt 2):F223-31.

33. Dickinson H, Moritz K, Wintour EM, Walker DW, Kett MM. A comparative study of renal function in the desert-adapted spiny mouse and the laboratory-adapted C57BL/6 mouse: response to dietary salt load. Am Physiol Soci 2007;293:F1093-98.

34. Wallimann T, Tokarska-Schlattner M, Schlattner U. The creatine kinase system and pleiotropic effects of creatine. Amino Acids 2011:1-26.

35. Wallimann T, Wyss M, Brdiczka D, Nicolay K, Eppenberger HM. Intracellular compartmentation, structure and function of creatine kinase isoenzymes in tissues with high and fluctuating energy demands: the 'phosphocreatine circuit' for cellular energy homeostasis. Biochem J 1992;281 (Pt 1):21-40.

36. Sestili P, Martinelli C, Colombo E, et al. Creatine as an antioxidant. Amino Acids 2011;40:1385-96.

37. Gualano B, Artioli GG, Poortmans JR, Lancha Junior AH. Exploring the therapeutic role of creatine supplementation. Amino Acids 2010;38:31-44.

38. LaRosa DA, Ellery SJ, Parkington HC, Snow RJ, Walker DW, Dickinson H. Maternal creatine supplementation during pregnancy prevents long-term changes in diaphragm muscle structure and function after birth asphyxia. PLoS One 2016;11:e0149840.

39. LaRosa DA, Ellery SJ, Snow RJ, Walker DW, Dickinson H. Maternal creatine supplementation during pregnancy prevents acute and long-term deficits in skeletal muscle after birth asphyxia: a study of structure and function of hind limb muscle in the spiny mouse. Pediatr Res 2016;80:852-60. 
40. Ellery SJ, LaRosa DA, Kett MM, et al. Dietary creatine supplementation during pregnancy: a study on the effects of creatine supplementation on creatine homeostasis and renal excretory function in spiny mice. Amino acids 2015:1-12.

41. Dickinson H, Ireland ZJ, Larosa DA, et al. Maternal dietary creatine supplementation does not alter the capacity for creatine synthesis in the newborn spiny mouse. Reprod Sci 2013;20:1096-102.
42. Gualano B, Ferreira DC, Sapienza MT, Seguro AC, Lancha AH Jr. Effect of short-term high-dose creatine supplementation on measured GFR in a young man with a single kidney. Am J Kidney Dis 2010;55:e7-9.

43. Gualano B, de Salles Painelli V, Roschel H, et al. Creatine supplementation does not impair kidney function in type 2 diabetic patients: a randomized, double-blind, placebo-controlled, clinical trial. Eur J Appl Physiol 2011;111:749-56. 